\title{
Embracing uncertainty: an empathy and resilience-based approach to cardiothoracic surgery in a post-pandemic era
}

\author{
Bashi V. Velayudhan ${ }^{1}$
}

Published online: 19 April 2021

(C) Indian Association of Cardiovascular-Thoracic Surgeons 2021

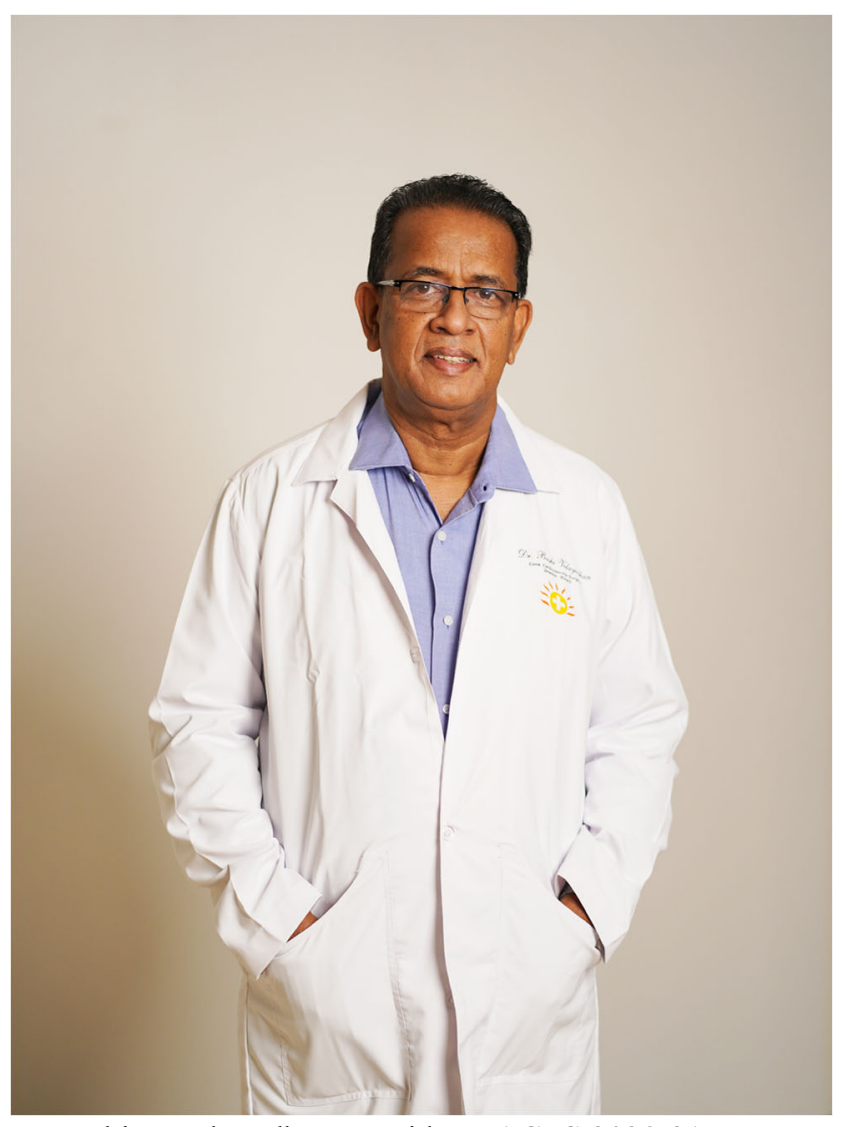

Dr Bashi V Velayudhan, President IACTS 2020-21

Colleagues and friends, I want to thank you for this opportunity to address you today. When I took on the presidency of the association a year ago, I would never have imagined the

Presidential address delivered at the virtual 67th Annual Conference of the Indian Association of Cardiovascular and Thoracic Surgeons, India, February, 2021.

Bashi V. Velayudhan

bashivv@hotmail.com

1 Institute of Cardiac and Aortic Disorders, SIMS Hospitals, Chennai, India trajectory the past 12 months have taken, and the circumstances that have led me to deliver this speech virtually for the first time in the history of the Indian Association of Cardiovascular-Thoracic Surgeons (IACTS).

This past year has challenged the Association in unimaginable ways. With the onset of the pandemic, we have had to fundamentally rethink how we connect with each other as individuals, and as a community. Our main aim as the Executive Committee at IACTS was to ensure that members were able to access learning and sharing opportunities, and get necessary support. I am very proud to say that we were able to adapt quickly and provide many opportunities, including the continued medical educations and masterclasses, to come together across virtual platforms. We have conducted a record of 244 masterclasses during this period. As a result, many members who would not have been able to join for an in-person meeting were able to access a variety of talks and discussions. A Covid-19 task force was formed and mobilised quickly to publish interim recommendations for surgeons during the pandemic. Producing these types of guidelines was a first for our association.

This year, as you know, our meeting was originally scheduled to be held in Jaipur. As the pandemic unfolded, the Executive Committee made the decision well in advance to move this to a virtual platform. Organising Secretary Dr. C.S. Hiremath has taken tremendous efforts to ensure that we can maintain the high scientific standards of the meeting, despite all the challenges. His tireless work throughout the year cannot go unmentioned. He spent many waking hours coordinating meetings and executing programmes and held the committee together as a strong unit.

The scientific committee under the leadership of Dr. K.S. Iyer has worked tirelessly to bring together a strong, experienced and engaging faculty. To all the members of the Executive Committee, I would like to express my deepest gratitude - without your dedicated time, support and active inputs, it would have not been possible to continue our work through this period.

One of the significant achievements that culminated this year was the indexing of our journal with PubMed Central. 
Under the expert leadership of Dr. O.P. Yadava, this has become a reality. This year, we have had a record number of teaching programmes - more than any other year in the history of the IACTS. I cannot forget to mention the endless hours of behind-the-scenes work being done by our valued staff member, Mr. Aditya, to support Dr. C.S. Hiremath.

I also want to take this opportunity to welcome the incoming president, Dr. K.S. Iyer, who has brought his vast expertise and knowledge to the IACTS in a different capacity in the past, and I am sure he will continue to do so in the future in his new role.

These unprecedented times remind me of one of the critical lessons I have learned over my 42-year journey in the field of cardiothoracic surgery - that despite all the medical advancements and innovations in the world, human life is unpredictable. We can never assume that we have all the answers.

Facing uncertainty has been a constant feature of my own life. As a son of a farmer, one of seven children, we were brought up in an agricultural household in rural Kerala. A myriad of variables affected our everyday lives in deep ways - from unpredictable weather, leading to floods, drought and eventually famine at times. Through it all, my parents provided me with a strong foundation to counter these challenges. They stressed the importance of education and hard work, inculcated values around equity and equality and ensured we treated others with dignity and respect. My father, a farmer, was a perfectionist and a firm believer in gender equality. He was well known in the community for his charitable nature. My mother played an important role in instilling discipline in all aspects of our lives (Fig. 1). It was not an easy job to raise, educate and encourage four girls and three boys! Both of them would be the happiest to see me standing here delivering this presidential address. So today, I would like to reflect on these life lessons, during what is arguably one of the most testing periods of our lifetimes.

Before I begin, I wanted to take a moment to pause and share a bit of my own journey. I joined the association as a member 40 years ago. I attended my first IACTS meeting in 1981 at Vigyan Bhawan where I was privileged to witness the late Dr. Denton Cooley's keynote address, chaired by the late Prof. Padmavati, one of the pioneers of cardiology in India. The late Dr. Cooley spoke of his experience with 17,000 coronary bypass surgeries at the Texas Heart Institute. As a young aspiring trainee, I could not fathom this-at the time, we were doing less than 200 bypass surgeries every year in all of India. The question that was going through my mind was: 'Could we ever make this a reality in our country; with all the challenges we face?' Back then, I could never have imagined the statistics today - when we are doing more than 100,000 coronary bypass surgeries a year.

My career has been intimately linked to this history and led me to where I stand today, following in the footsteps of many leaders in our field who have paved the way for all of us. Amongst them, I want to take a moment to acknowledge those who are responsible for laying the foundation of my long career in the field. The late Prof. P.K.R. Warrier and the late Prof. M.R.S. Menon of Trivandrum Medical College were responsible for seeing the potential in a wide-eyed young man from Kalady. Prof. P.S. Jayaraj and Prof. S. Muralidharan, two individuals who shared their wisdom with me about surgery and much more, still continue to inspire me. A turning point of my career was at the Royal Adelaide Hospital working under Dr. David Craddock along with Dr. Iain Ross and John Stuburfield, who gave me an opportunity to fine-tune the art of coronary
Fig. 1 My parents. a Father-Mr. Velayudhan. b Mother-Mrs. Karthiayani
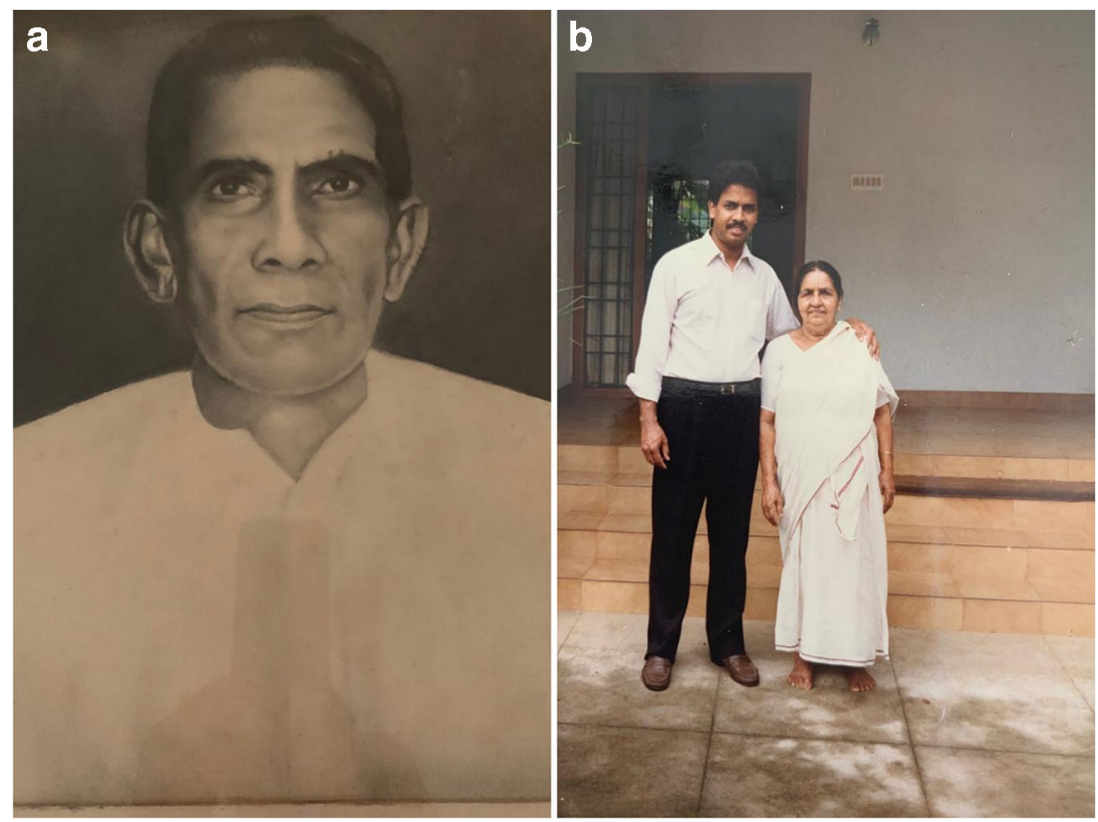

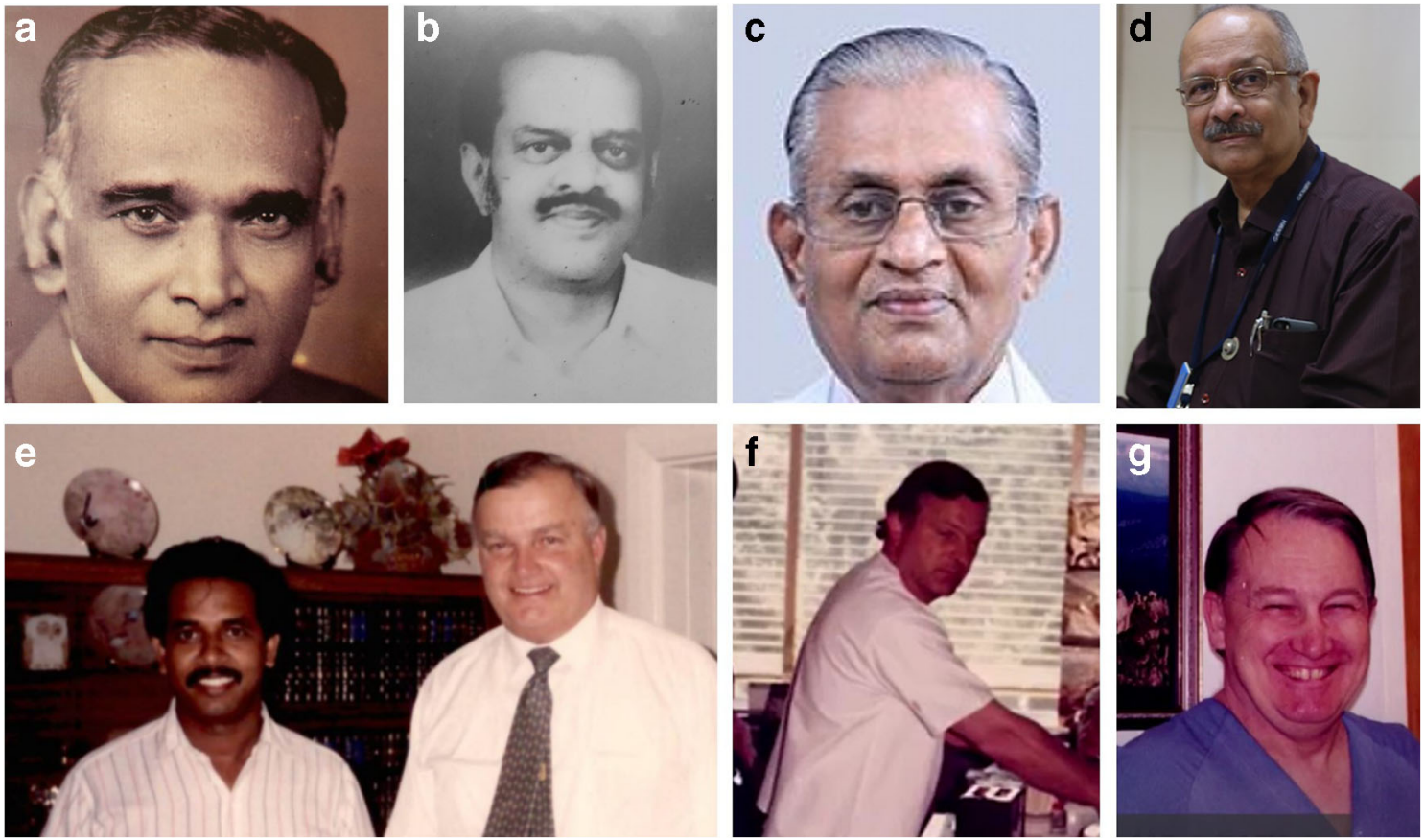

Fig. 2 My teachers. a Prof. P.K.R. Warrier, b Prof. M.R.S. Menon, c Prof. P.S. Jayaraj, d Prof. S. Muralidharan, e Dr. David Craddock, f Dr. Iain Ross, g Dr. John Stuburfield

bypass surgery at a time when there was a need for more specialists in this field in India (Fig. 2). I will always be grateful for

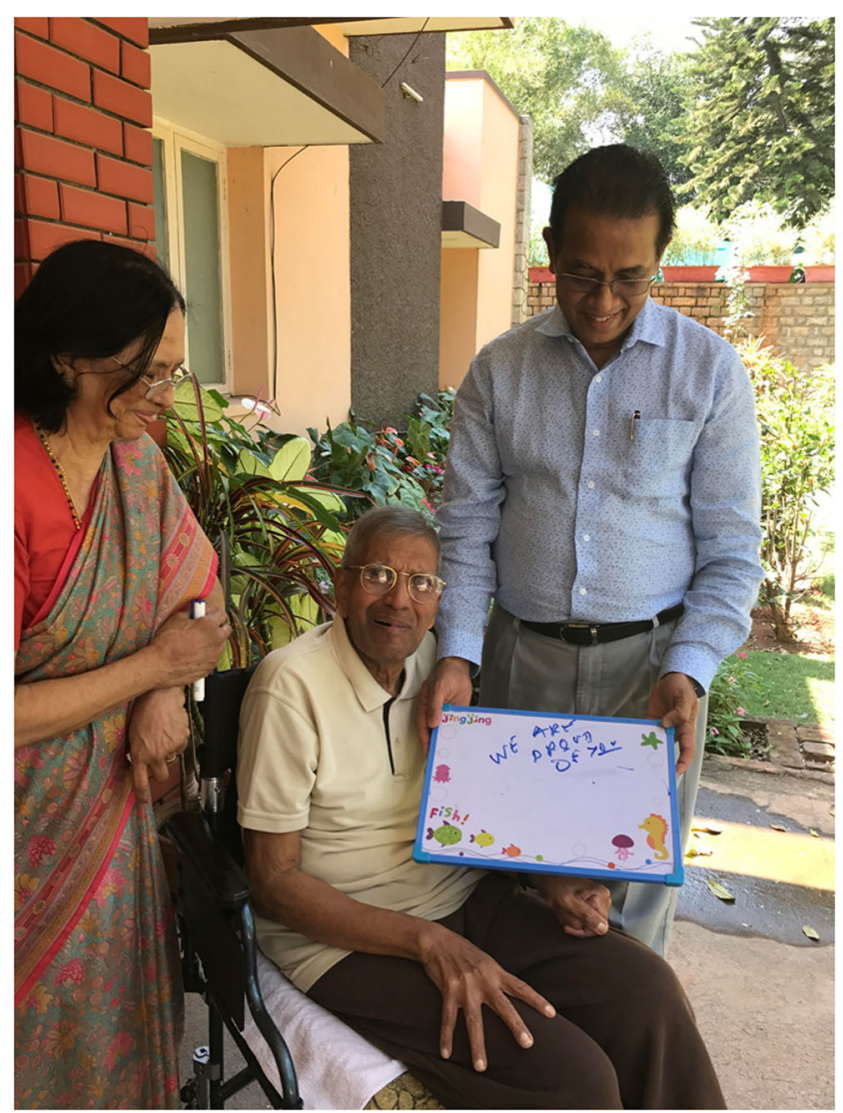

Fig. 3 My mentor, Prof. Stanley John, with Mrs. Lilly John the years spent with Dr. Craddock in his department. Last but not the least, words are not enough to pay tribute to the late Prof. Dr. Stanley John, who nurtured my skills from a sapling to what they are today. He taught me more than I can express. Suffice to say his teachings guide me in my work and life. My tribute to him is to pass his knowledge on to generations of surgeons ahead (Fig. 3).

In June 1980, a month after I got married, I joined the Department of Cardiothoracic Surgery of Christian Medical College Hospital, Vellore. Today, when I look back, I cannot quantify the years of sacrifice and invisible and immeasurable labour that my wife of 41 years, Sethu, has put in. There were times when she had to take the lead in raising our two girls while I had to endure years of 18-h days and sleepless nights. Her strength and conviction are an inspiration to me. She imbibed in our children a sense of service, and has always pushed them to fulfil their dreams. Those close to us know of her amazing creativity, which she shares with others generously. It is also no secret that she always puts the finishing touches on all my presentations! My daughters, Gayathri and Gopika, while not following my specific career path, have chosen fields of social significance and impact and continue to make me proud (Fig. 4).

Like many presidents before me, deciding on what to focus on today was a big challenge. With so many critical issues to discuss in the field of cardiothoracic surgery, and a once-in-alifetime opportunity to address you all, I could not think of anything to say that you have not heard before. But given that we are in a unique historical moment, I have decided to 
Fig. 4 My family (2019)

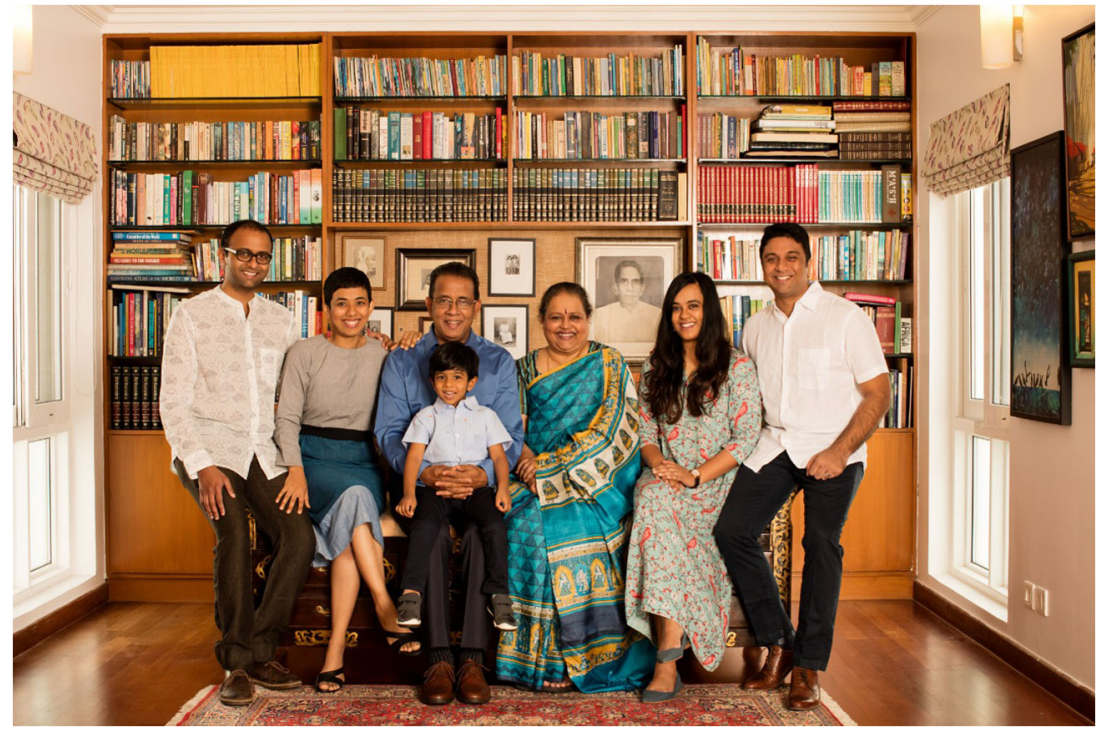

present my reflections around a simple idea: embracing uncertainty — with empathy and resilience.

The Covid-19 pandemic has laid bare the ability of humankind to set off chains of unpredictable events. While epidemiologists globally may understand the mechanics of outbreaks, there is still a range of differing opinions on how, when and where the next outbreak could occur [1]. This kind of uncertainty will arguably be a constant characteristic of our future as well, but it does not mean that we do not have the power to change things.

When I look around me, I see a world that is filled with fear and anxiety. In addition to an emphasis on public health measures, the pandemic has led to a crisis of mental healthmaking everyday decisions has become a mammoth task for many. It made me think about how we, as cardiothoracic and vascular surgeons in India, have and will no doubt continue to face a number of uncertainties as our field progresses.

How have we historically dealt with uncertainties across our field - from disease patterns and treatments to medical education and training? And how can we prepare ourselves for uncertainties in the future? Is there anything we can learn from our journeys? Today, I would like to share my reflections on these questions with you all-drawing from my own life experiences and those of the people who have influenced my work, life and thinking. I hope that in some way I might offer some food for thought at this critical juncture.

Let me take you back for a moment to May 1986. I was 33 years old. I must have completed 300 open-heart surgeries and I was standing in the operation theatre. After excision of the mitral valve, the heart-lung machine suddenly stopped; we were plunged into darkness. The only light available was that of a laryngoscope. There had been a power failure and the back-up generator had also failed. The patient's temperature was $28{ }^{\circ} \mathrm{C}$. For $14 \mathrm{~min}$, there was no power. I stood and prayed. Once the power came back, we completed the surgery. The patient did well and was eventually discharged.

Today, when I look back at that moment, I can say that we have truly come a long way in the last 40 years. I have been able to witness a period from when the biggest challenge was the availability of a constant electricity supply to today when our challenge is countering the misinformation that patients receive from 'Dr. Google'. With available resources, we are treating complex cases and have increased the reach of our work to remote corners of the country, and even the world. I am proud to be part of our ever-growing community of cardiovascular and thoracic surgeons, and to have witnessed this tremendous change and growth in my lifetime.

We have dealt with many uncertainties in our field - some in our control and others that have been impossible to predict. Many would say that our field is at a crossroads now-with low enrolment rates, challenges in training, a population vulnerable to heart disease and technological advancements. We face a future that demands us to have a conversation that strikes at the 'heart' of what we do. I would like to touch on the different kinds of uncertainties that I feel are relevant to these issues.

\section{Uncertainty in training cardiothoracic surgeons}

When we talk of uncertainty, I want to start at the very beginning of how each and every one of us got here - our education and training. As we sit together today, we cannot ignore the fact that $70 \%$ of cardiothoracic and vascular surgery seats in India are vacant. While there may be no single reason that contributes to this (and admittedly there are many reasons 
out of our individual control), it is certainly a cause for concern and reflection for us all.

My observation is that young medical graduates face many unknowns. In a world of too much information and high financial and social pressures, they are faced with difficult decisions and choices. In our field, the path is long and the learning curve steep. We are placed in tough working conditions, and unfortunately, early in this career, as all of you have experienced, the monetary benefits are not commensurate to the rigors of the work. Women continue to face significant societal and institutional barriers, preventing them from being able to advance in this field. This is not something we can ignore.

For those undergoing training, rapid developments in cardiac surgery over the past $10-15$ years have placed a huge responsibility on teachers and trainers to keep up with everevolving minimally invasive techniques. I often wonder what this means for our training programmes - how can we remain relevant and innovative? How can we ensure that we are doing the very best for our patients? I will come back to this question a little later.

\section{Uncertainty in disease patterns}

Fifty years ago, the cardiac diseases and treatment pattern in our country were totally different. As I reflect back on the operations that were performed in 1982 when I completed training, there is little resemblance of the work that is being done all over the world today. As the Greek philosopher Heraclitus said - 'the only constant is change'.

Thanks to improvements in our health care systems, rheumatic heart disease has decreased to a large extent. Proportionately, lifestyle diseases like coronary artery disease have increased. This could partly be due to increased life expectancy. When I joined cardiac surgery, patient survival was big news, whereas today, losing a patient is framed as a mistake.

Fifty years from now, we will be facing a totally unique set of issues. We can aim to predict what these might be, but the reality may be a different story. I am sure it would be beyond our own imaginations. During my training, I could never have comprehended operating on a beating heart! None of this should deter us from trying new things. We must accept rapid changes in disease patterns and be prepared to adapt and adjust.

\section{Uncertainty in technological advancements}

The emergence of new technologies in surgical procedures cannot be underestimated. In the pursuit of eliminating uncertainties, our speciality has not become extinct, nor has it diminished — instead, it has survived and thrived. Thoracic aortic diseases and aortic dissections being handled by endografts, replacements of valves and other structural heart disease by percutaneous methods, development of robotics and artificial intelligence (AI) are a few significant advancements over the last decade alone. However, the assumption that the pervasive use of technology alone will drive the field forward is problematic. We need to think more deeply about the 'how' and the 'when' of its use.

Recently, I heard a cardiac surgeon talk about how he does not go to the postoperative cardiothoracic surgical intensive care unit (ICU) to see patients, highlighting the advantages of being able to monitor and care for patients remotely. How ironic is it that many patients often just crave the human touch, to meet their surgeon and share their problems in the immediate postoperative period. Though it may seem here that technology provides us with a 'quick fix', in this case, I would argue that we think twice before generalising about the advantages of 'taking rounds on a cellphone' (Fig. 5).

\section{Empathy in the face of future uncertainty}

So how can we move into the future of cardiothoracic surgery, keeping in mind the uncertainties that I have touched on today? Since the beginning of human civilization, our survival has been largely due to the incredible ingenuity of our species. Now, more than ever, as vaccines are rolled out at record speed around the world, it seems that our ability to overcome adversity is limitless.

But, as we all know, technocratic solutions will not be enough to tackle the 'big-picture' problems that we will continue to face. History has shown us time and time again that advancements and innovation can only succeed when we truly embed them in our diverse social and cultural contexts. I want to share a little bit about a simple, core principle that cannot be over-emphasised - that of empathy. I have always felt that in cardiac surgery specifically, holding true to this principle will carry us forward into the millennia ahead - regardless of all the technologies we may harness.

A true expert is someone who can educate and empathise with patients, their relatives and loved ones, to ensure that they are prepared, physically and mentally, for any treatment. Beyond diagnosis and explaining the course of treatment, sometimes we forget to guide them through the mental trauma that they may face. One of the things I often share with patients, who are suddenly faced with a major heart problem, is what I call the three 'A's: accept, adapt and adjust (Fig. 6). I found that this helps quell the anxiety of patients and their families, even if just temporarily.

Studies have shown, however, that there is a steady decline in empathy that starts from medical school and progresses well into training [2]. Surgeons are particularly susceptible - since our 
Fig. 5 Physical examination in the cardiothoracic ICU and in the postoperative ward
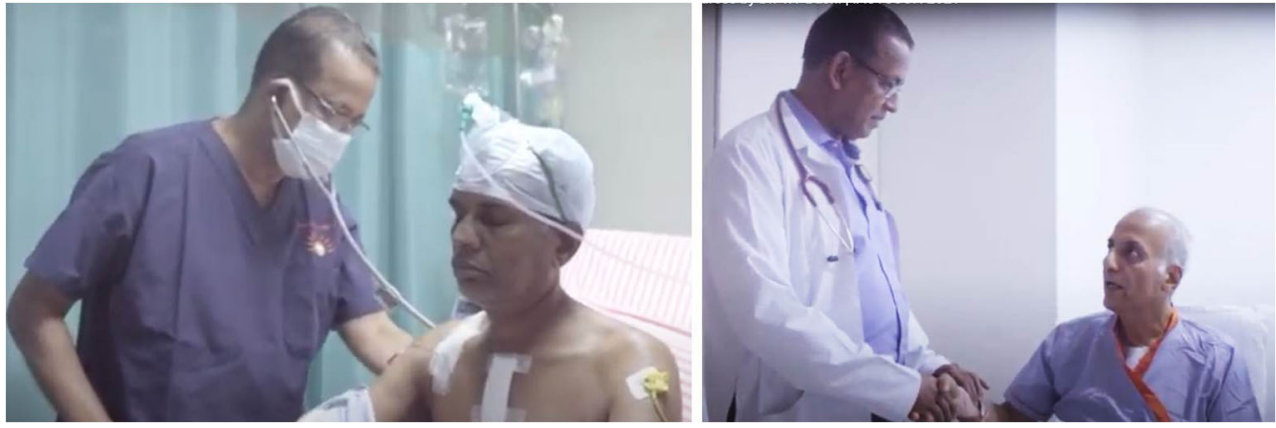

formal training does not focus on, or incentivise, practicing these values. Where does this leave us? In a post-pandemic world, when the medical community itself has faced an unprecedented global challenge, it is now more than ever that we need to reinvest in building empathy and resilience within our profession more broadly. This is not as easy as it seems. The expression of emotions in medical practice is often perceived as unprofessional, and many doctors learn to suppress and ignore their feelings. When faced with stressful situations, these physicians are more likely to suffer from depression and burnout than those who engage with and reflect on their feelings [3]. With increasing levels of uncertainty across different sectors, this is something we must invest in.

In the context of training, this means as senior surgeons we need to have the patience and humility to step back and give space to the ideas and experience of our mentees. My advice to those who are starting out in this field is - do not ever feel that your opinions are not valid and important. I was privileged to have worked with stalwarts in this field who allowed me the space to learn and then, more importantly, to implement my own learning. When I joined Trivandrum Medical College in 1977, Dr. MRS Menon was the chief of cardiovascular surgery. I was assisting for a closed mitral valvotomy for the first time. He asked me what the qualities

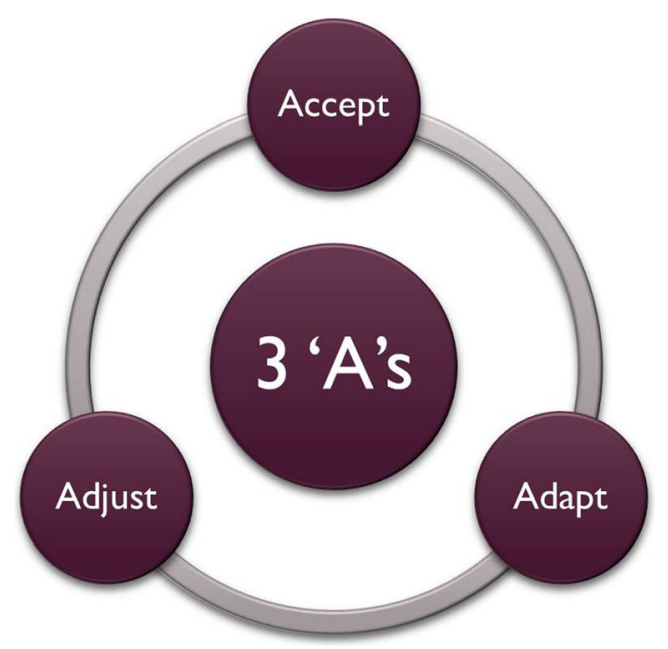

Fig. 6 Three 'A's: accept, adapt and adjust — helping to quell the anxiety of patients and their families prior to surgery of a good cardiac surgeon are. I was not able to give him the answer. Then he told me- 'A good cardiac surgeon doesn't make mistakes, because a good surgeon will not operate without a good assistant and anaesthetist. Now you are the senior surgeon, and I'm your assistant-you go ahead and feel the valve. Whatever happens does not take your finger out of the left atrium'. The way he spoke to me inspired so much confidence. I remember that advice till today.

Empathy must extend from the classroom to the consultation room, the operation theatre and beyond. Whenever a patient comes to me, I always think about how grateful I am that I am not on the other side of the table. When I talk to the patient, in my mind, I swap places with them. Being in their shoes, my only thought would be-'how can this doctor help me to overcome my fears, questions and anxieties about my situation?' We need to hold back our urge to share our diagnosis immediately, and instead provide the patient with the space and time they need.

While we get caught up in the everyday struggles of our profession, let us not forget the incredible power of something so primal-human touch. I remember a time when I operated on a senior ophthalmologist. After the operation, he ran a temperature for three days; we could not understand why. During my rounds, I held his hand and examined him physically. He went on to recover well, and returned home. Three months later, when he came to see me, he mentioned that on the day I visited and examined him when he was very sick, he felt a huge sense of relief, not just mentally but physically as well. I was struck by how much just the simple act of physical touch by the doctor seemed to be so important to his recovery. I have never underestimated this healing power that we hold, and it is not something I take for granted.

Lastly, let us try not to lose our temper inside the operation theatre; it increases the likelihood of making mistakes. This is not easy, but it always helps to have a strong and trustworthy team at your side. I have been blessed to be surrounded by incredible teams across the many years, both young and old. Someone who knows every thought of mine, Senior Anaesthetist Dr. Aju Jacob, has been an irreplaceable part of my team for the past 30 years. He gives equal importance to the look of the heart and the monitors - a unique and important trait for any anaesthetist in the cardiac operating theatre. 


\section{Building resilience in our field: the long run}

While our everyday practice must be embedded in empathy, an analysis of our field as a whole must be visionary and bold. It requires a lot of patience and imagination, and a tremendous amount of what I would like to talk about next: resilience.

You would agree that one of the biggest global challenges of our times continues to be that of climate change. Climate scientists and experts, who are dedicated to finding global solutions to this issue, speak often of 'climate resilience'. Climate resilience can be generally defined as the capacity for a socio-ecological system to do two main things: (1) absorb stresses and maintain function in the face of external stresses imposed upon it by climate change and (2) adapt, reorganise and evolve into more desirable configurations that improve the sustainability of the system, leaving it better prepared for future climate change impacts [4].

If we draw parallels, resilience in our field could be defined as our ability to deal with the health challenges that will surely arise due to changes in the environment, our lifestyles and broader socio-political changes. The pandemic has raised questions about the status quo across the board; it is no longer enough to proceed 'as normal' now. We need to think more deeply about our 'desirable configurations' that can improve sustainability.

Our focus on resilience must extend from education and training right up to patient care. We must be ready as leaders to invest in building strong, innovative systems to face the future and to ensure that our field remains relevant in the years to come.

On the topic of training, I recently came across a wellarticulated piece in the Journal of the American College of Cardiology (JACC), which recognises an ongoing 'paradigm shift' in the management of structural heart diseases, through new endovascular platforms [5]. The authors have summarised some critical and practical solutions directed at trainees, to thrive during what they refer to as a 'transition within a transition'. This is a time during which trainees are expected to take on clinical responsibilities and acquire new skills, as well as predict changes in the landscape of cardiovascular surgery. I believe they are applicable to all of us during this time of seismic shifts. Here is a summary of these solutions:

1. Embrace the unremitting transitions inherent in any dynamic and academic discipline.

2. Be willing to engage in new experiences, even if they appear to deviate from your predetermined long-term plan.

3. Be deliberate in practising a new skillset to prevent being deterred by the learning curve.

4. Engage in social or academic interdisciplinary gatherings to exchange ideas and to collaborate on projects.

5. Seek diverse mentors who may be able to connect you to new learning opportunities.

6. Attend conferences or seminars on new devices or clinical trials to explore new technologies.
While these are important words of advice for trainees, we must also recognise that innovative and bold steps must be taken by mentors to help trainees navigate this 'transition within a transition'. There needs to be much more flexibility in allowing trainees to pursue opportunities to grow their skills and knowledge during the latter part of their training programmes. This would require some radical steps to restructure the training programme. Are we ready to make this a reality?

Resilient systems also require combined thinking and interdisciplinary knowledge. For example, in the context of aortic surgery, complex surgeries were not being done till the last 15 years, when we had the opportunity to meet and interact with international experts in the field. The combination of their expertise, and our knowledge about context and disease patterns in India, led to a rapid development of aortic surgery in recent years. Without these kinds of exchanges, our systems would remain stagnant (Fig. 7).

Being a resilient system also means ensuring that everyone, including the most vulnerable and marginalised, should be able to access life-saving treatments. In India, we have the unique ability, as a fast-developing country, to help other developing nations overcome challenges like this. Unfortunately, lack of data and research has been one of the restricting factors. While individual hospitals or surgeons may document specific cases, having a bird's-eye view of what is happening in our discipline is critical.

As of this year, we have taken a significant step towards this: after much hard work, we are launching the IACTS database today. This ambitious project will allow us to collect data from different centres and to analyse in greater detail the status of cardiothoracic surgery in India. For this initiative to succeed, we will need all of your cooperation and participation. The rich analysis that can be harnessed from this will not only be useful to us as a community but also be beneficial to those of us who present our work at international forums. I hope we all can work together to make this a reality in the years to come.

\section{A final word: coming together in the 'new normal'}

Our gathering today marks close to one year since the pandemic changed our lives irreversibly. For many of us, it has hit too close to home. My thoughts go out to those amongst us who have had to bear personal loss through this time. It seemed unimaginable during lockdowns that we would be here today, with vaccinations being carried out across the world, and in our country as well.

Covid-19 has taught us that despite our best laid plans and preparations, the future remains uncertain. In today's world, predictability is the most valued principle. Our smartphones have provided us with the capability to predict everythingfrom the weather to the number of steps we need to take every day. But this in no way means that everything can be predicted. 


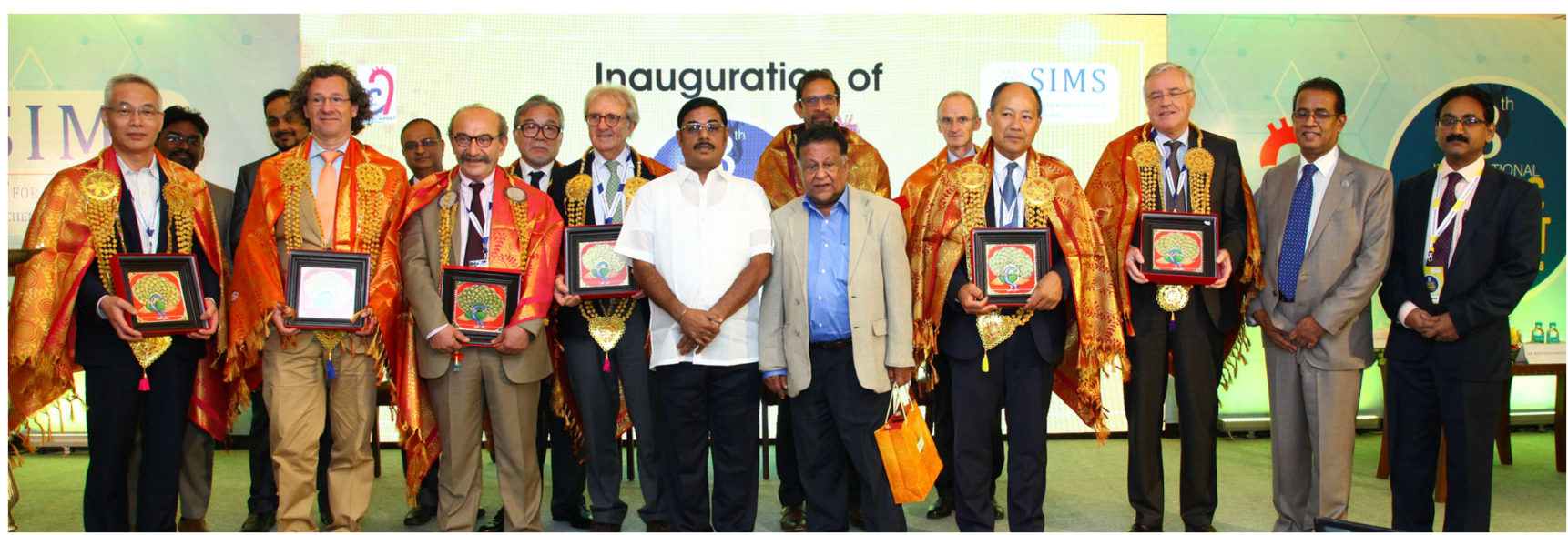

Fig. 7 International faculties at the inauguration of the 8th International Aortic Summit, Chennai, 2018

It is our ability to adapt and be prepared, resilient and empathetic that will enable us to take confident strides into the future.

We, as cardiovascular and thoracic surgeons in India, must rise to the occasion as we have historically done. We have advanced this field over the last number of decades, despite the many constraints and daunting challenges. Early in my career, I have given referral letters to patients who could afford to go to Texas Heart Institute for coronary bypass operations. Those days, I dreamt that we would one day be able to provide patients with world class care in our own country. Across my whole career, I have witnessed this dream become a reality.

The decisions we make now will have a huge bearing on both our individual and collective future. And every small decision makes a difference. When I finished my MBBS, my father developed inoperable stomach cancer. I was in a dilemma-should I stay to look after him or join the post graduate (PG) course? He told me that my future was important and that he may not be alive to see me complete the course. My parents' consistent emphasis on pursuing education helped me make that decision to pursue my postgraduate studies. This, and all the other decisions and learnings, helped me to be where I am today. So, while the future may seem uncertain, we have the power to change its course.

I have always believed that being a cardiac surgeon means fulfilling many roles: one of a leader, a teacher, a team builder and someone who displays compassion and empathy to their patients. Let us embrace all these identities, take care of and work with each other as we move forward in this 'new normal'.

I leave you today with a prayer from the Taittiriya Upanishad:

\section{Om Sahana Vavatu \\ Sahanau Bhunaktu}

\section{Saha Viryam Karavavahai \\ Tejasvi Navaditamastu \\ Ma Vidvishavahai \\ 'May the lord protect and bless us. \\ May he nourish us, giving us strength to work together \\ for the good of humanity. \\ May our learning be brilliant and purposeful. \\ May we never turn against one another.'}

Thank you for this opportunity to address you all.

\section{Declaration}

Conflict of interest The author declares no competing interests.

\section{References}

1. https://www.vox.com/science-and-health/2020/5/20/21257136/ covid-19-future-pandemic-chaos. Last accessed on $28^{\text {th }}$ March, 2020

2. Han JL, Pappas TN. A review of empathy, its importance, and its teaching in surgical training. J Surg Educ. 2018;75:88-94. https:// doi.org/10.1016/j.jsurg.2017.06.035.

3. Kerasidou A, Horn R. Making space for empathy: supporting doctors in the emotional labour of clinical care. BMC Med Ethics. 2016;17: 8. https://doi.org/10.1186/s12910-016-0091-7.

4. Nelson DR, Adger WN, Brown K. Adaptation to environmental change: contributions of a resilience framework. Annu Rev Environ Resour. 2007;32:395-419.

5. Han JJ, Brown C, Swain JD. Surgical training in an era of change and innovation: transition within a transition. J Am Coll Cardiol. 2019;74:814-7. https://doi.org/10.1016/j.jacc.2019.07.001.

Publisher's note Springer Nature remains neutral with regard to jurisdictional claims in published maps and institutional affiliations. 